\title{
PREGNANT WOMEN ASPECTS REGARDING CHILDBIRTH PREFERENCES AT UNIVIVERSITY HOSPITAL
}

\author{
P.J. Nader, S.S. Nader, M.R.K. Iorra \\ Universidade Luterana do Brasil, Canoas, Brazil
}

Introduction: Pregnancy is a unique experience in a women's life, fulfilled with expectations, surrounded by uncertainties and cultural resistances. The present study describes pregnant women their major concerns regarding childbirth preferences.

Methods: Descriptive study of serial samples acquired from May $1^{\text {st }}$ of 2010 until June $30^{\text {th }}$ of 2010 . A questionnaire was applied to 400 pregnant women in ULBRA University Hospital rooming-in care facility, regarding variables concerning preferences on childbirth delivery.

Results: Gravida's preference of vaginal delivery was observed at $72.8 \%$ of the time. Their main arguments for such preference were: faster recovery, lesser pain and suffering, faster method of delivery and decreased risk of mother's death. Variables concerning their choice of way of delivery were: presence of a partner, educational level, home income, and time rupture of membranes. Main medical indication for cesareansection was cephalopelvic disproportion (22.6\%), and $35 \%$ of the women believed that it was failure of labor induction, their indication for abdominal delivery.

Conclusion: Vaginal delivery found to be their preferable way of delivery $(\mathrm{n}=291)$.

Group who preferred vaginal delivery profile: younger age, highest level of education, higher income, having a fixed partner, and shorter time of membrane rupture. Discordance among gravida's alleged causes and medical indication for cesarean section was observed. 